\title{
Climate change, collections and the classroom: using big data to tackle big problems
}

\author{
Eileen A. Lacey ${ }^{1}$, Talisin T. Hammond ${ }^{1 *}$, Rachel E. Walsh ${ }^{1}$, Kayce C. Bell ${ }^{2}$, Scott V. Edwards ${ }^{3}$, Elizabeth R. Ellwood ${ }^{4}$, \\ Robert Guralnick ${ }^{5}$, Stefanie M. Ickert-Bond ${ }^{6}$, Austin R. Mast ${ }^{4}$, John E. McCormack ${ }^{7}$, Anna K. Monfils ${ }^{8}$, \\ Pamela S. Soltis ${ }^{5}$, Douglas E. Soltis ${ }^{5,9}$ and Joseph A. Cook ${ }^{2}$
}

\begin{abstract}
Preparing students to explore, understand, and resolve societal challenges such as global climate change is an important task for evolutionary and ecological biologists that will require novel and innovative pedagogical approaches. Recent calls to reform undergraduate science education emphasize the importance of engaging students in inquirydriven, active, and authentic learning experiences. We believe that the vast digital resources (i.e., "big data") associated with natural history collections provide invaluable but underutilized opportunities to create such experiences for undergraduates in biology. Here, we describe an online, open-access educational module that we have developed that harnesses the power of collections-based information to introduce students to multiple conceptual and anaIytical elements of climate change, evolutionary, and ecological biology research. The module builds upon natural history specimens and data collected over the span of nearly a century in Yosemite National Park, California, to guide students through a series of exercises aimed at testing hypotheses regarding observed differences in response to climate change by two closely related and partially co-occurring species of chipmunks. The content of the module can readily be modified to meet the pedagogical goals and instructional levels of different courses while the analytical strategies outlined can be adapted to address a wide array of questions in evolutionary and ecological biology. In sum, we believe that specimen-based natural history data represent a powerful platform for reforming undergraduate instruction in biology. Because these efforts will result in citizens who are better prepared to understand complex biological relationships, the benefits of this approach to undergraduate education will have widespread benefits to society.
\end{abstract}

Keywords: Climate change, Instructional modules, Natural history, Specimens, Undergraduate education

\section{Background}

Global climates are changing at an unprecedented pace (IPCC 2014). These changes have critical implications for humans, including alterations to food production (Nelson et al. 2014; Vermeulen et al. 2012), loss of economically important ecosystems (Hanewinkel et al. 2013; Hannah et al. 2013), and emergence of new pathogens and diseases (Altizer et al. 2013; Kutz et al. 2009). Each of these threats is also integrally tied to changes in global biotas, making efforts to understand the impacts

\footnotetext{
*Correspondence: thammond@berkeley.edu

${ }^{1}$ Museum of Vertebrate Zoology \& Department of Integrative Biology,

University of California, Berkeley, CA 94720-3140, USA

Full list of author information is available at the end of the article
}

of climate change on the evolutionary and ecological dynamics of biodiversity essential to nearly all aspects of modern biology. Accordingly, training future generations of biologists-as well as an informed public-will increasingly require understanding of the concepts, skills, and data needed to evaluate changes to biodiversity and the associated impacts on humans. Because natural history collections serve as vast, often untapped, repositories of knowledge regarding global biodiversity (Graham et al. 2004; Page et al. 2015; Ponder et al. 2001; Pyke and Ehrlich 2010; Wen et al. 2015), we believe that undergraduate learning experiences that capitalize upon these invaluable resources will be particularly effective in training students to aggregate, analyze, and interpret the biological data sets needed to address the challenges that 
lie ahead. Here, we describe newly developed classroom exercises that make use of emerging biodiversity informatics resources-"big data"-obtained from museum specimens to provide authentic, inquiry-driven, placebased instruction in the scientific principles and procedures underlying modern climate change research.

\section{Climate change: a call for new forms of science education}

Climate change research is inherently interdisciplinary, incorporating elements of diverse disciplines such as ecology, geology, chemistry, evolutionary biology, sociology, geography, urban and regional planning, earth and planetary sciences, agriculture, and medicine. Preparing students for a world in which the effects of climate change are omnipresent requires a new model for science education-one that emphasizes the intellectual and practical abilities needed to work across disciplines to develop responses to global challenges (Melillo et al. 2014; Plutzer et al. 2016). The need for new models of education is exacerbated by ongoing declines in literacy in science, technology, engineering, and mathematics (STEM) in the United States (Brewer and Smith 2011; PCAST 2012). Science education is at a critical juncture, with the effectiveness of current classroom strategies being questioned just as pressing new needs are emerging. Rather than viewing these as orthogonal or even opposing problems, we believe they can act in concert to offer exciting opportunities for educational reform. Specifically, we suggest that efforts to equip students with the knowledge and skills required to address global climate change provide a perfect opportunity to enact more general changes in undergraduate science education to bring pressing issues into the classroom.

\section{The foundation: climate change, biodiversity, and natural history collections}

Natural history collections provide a particularly effective vehicle for educators to engage students in inquiry-based learning through exploration of the extensive resources associated with museum specimens (Cook et al. 2014; Powers et al. 2014; Monfils et al. in press). The millions of physical specimens housed in such collections represent an irreplaceable record of global biodiversity (NIBA 2010). Increasingly, these specimens are linked to a rich array of additional information such as genetic sequences, records of parasites and pathogens, field observations of behavior, ecological information derived from stable isotope analyses, and habitat assessments based on remote-sensing satellite data (Cook et al. 2016). Because specimens and all associated data are both georeferenced and time-stamped, they provide critical resources for examination of changes in biodiversity over space and time (Johnson et al. 2012; Lister 2011; Wandeler et al. 2007). As a result, an increasing number of studies are using direct comparisons of historical and modern natural history specimens and associated information to document the impacts of climatic change (Moritz et al. 2008; Rowe et al. 2014; Tingley et al. 2009).

\section{Big data, big opportunities}

Until recently, access to the information contained in natural history collections was limited primarily to curators and the subset of researchers engaged in studies of traditional museum disciplines such as taxonomy and systematics. With the explosive increase in digitization of natural history collections, however, many of the constraints on specimen use have been eliminated (Holmes et al. 2016). Indeed, the contents of many collections are now digitally available to anyone with internet access. This includes information regarding taxonomic identities, georeferenced localities, collection dates, and critical life history parameters such as sex, reproductive status, and relative age (Fig. 1; Cook et al. 2016). For an increasing number of specimens, data regarding genetic variation are also available online (e.g., GenBank, www.ncbi. nlm.nih.gov/genbank/). Coupled with the growing array of mapping and analytical tools for analyzing natural history data (e.g., Berkeley Mapper, http://berkeleymapper. berkeley.edu/; Map of Life, www.mol.org), the result is a phenomenal bioinformatics toolkit for exploring the impacts of climate change on biodiversity.

While the use of natural history "big data" to explore organismal responses to environmental change has skyrocketed over the past decade (Rowe et al. 2014; Rubidge et al. 2011), the value of these resources to undergraduate education is just beginning to be realized (Cook et al. 2014). As the ease of accessing and analyzing the wealth of information in natural history collections continues to increase, the opportunities for creating significant and exciting learning experiences for students are growing. To illustrate the educational potential of these resources, below we outline an educational module that capitalizes upon natural history "big data" to engage students in inquiry-driven learning experiences that explore complex, real-world responses to environmental change. This module is one of several developed as part of AIM-UP!, an NSF-funded Research Coordination Network created to enhance the use of natural history collections in undergraduate biology education. All materials needed to use this module, including detailed guidance for educators as well as instructions regarding the download and installation of necessary software, are freely available online at http://aimup.unm.edu/for-educators/Climate\%20change.html. 


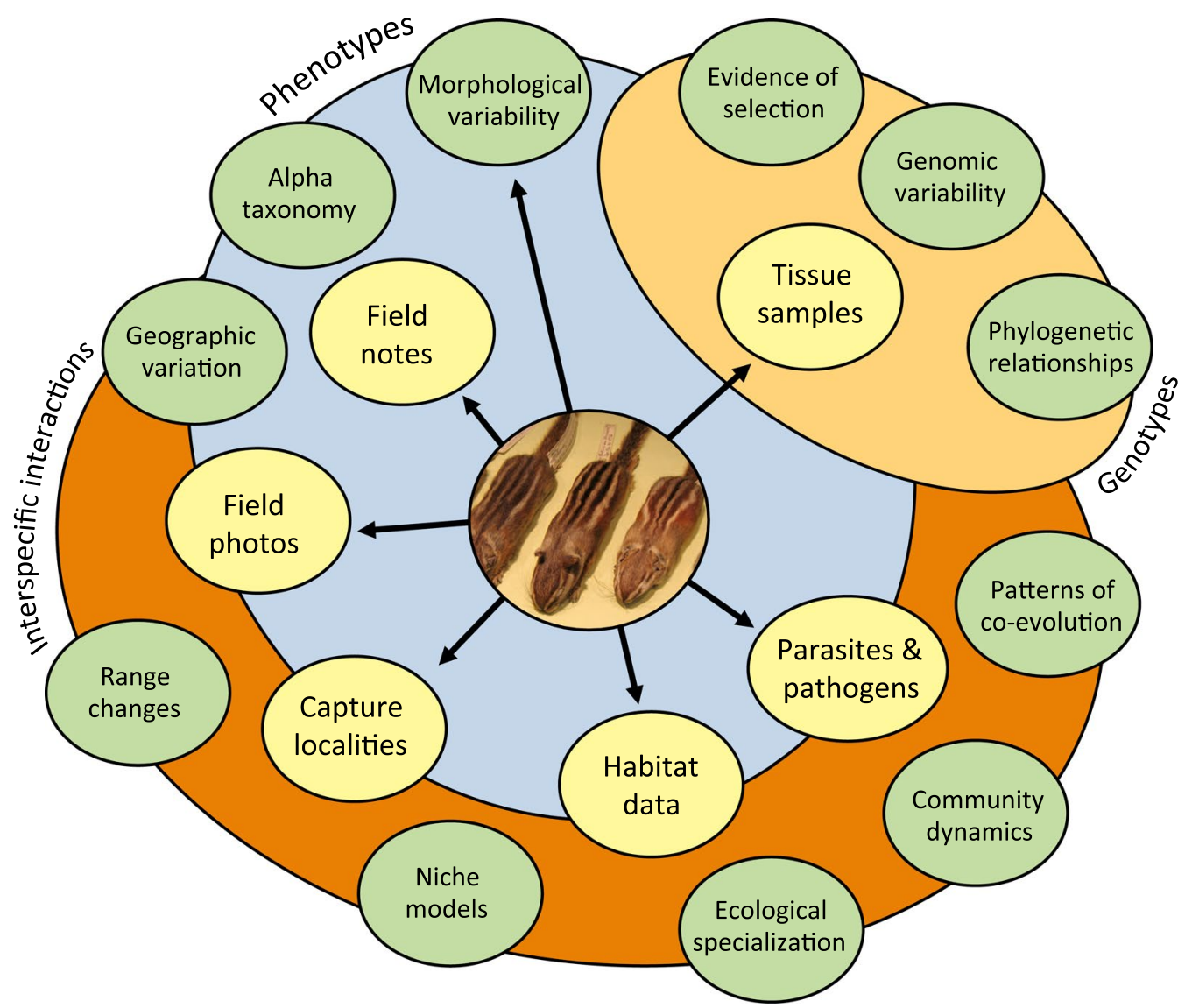

Fig. 1 Types of natural history museum data. Natural history specimens form the core of a large, integrative network of information that can be used to address numerous questions regarding environmental and climate change. In addition to traditional physical specimens (e.g., skins and skulls), data collected in the field (yellow circles) include photos, field notes, capture localities, and tissue samples. These materials, in turn, are used to document multiple aspects of an organism's biology (green circles), including elements of genotypic and phenotypic variation as well as interspecific relationships such as parasite-pathogen dynamics, co-evolutionary relationships, and biotic community structure

\section{The Grinnell resurvey project: using museum resources to document climate change}

Joseph Grinnell was the first Director of UC Berkeley's Museum of Vertebrate Zoology (MVZ). From 1914 to 1920, Grinnell and other members of the MVZ conducted extensive faunal surveys of the Sierra Nevada Mountains of California, with an emphasis on the Yosemite region in the central Sierra Nevada (Fig. 2). This undertaking produced more than 2700 museum specimens, as well as more than 2000 pages of handwritten field notes and over 800 photographs of California animals and their habitats. In addition to providing the first detailed characterization of the vertebrates of the Yosemite region (Grinnell and Storer 1924), these materials represent an invaluable and enduring record of faunal diversity in Yosemite in the early $20^{\text {th }}$ century. The importance of this resource was evident to Grinnell, who in 1910 wrote:
At this point I wish to emphasize what I believe will ultimately prove to be the greatest value of our museum. This value will not, however, be realized until the lapse of many years, possibly a century, assuming that our material is safely preserved. And this is that the student of the future will have access to the original record of faunal conditions in California and the west, wherever we now work.

"The Uses and Methods of a Research Museum" Popular Science Monthly

In 2003, as the MVZ approached its centennial, thenDirector Craig Moritz chose to put Grinnell's prescience to the test by launching an extensive re-survey of the Yosemite region, an undertaking that has become known as the Grinnell Resurvey Project (GRP). Working from the extensive records provided by the original survey, this modern effort, completed during 2003-2006, revisited 


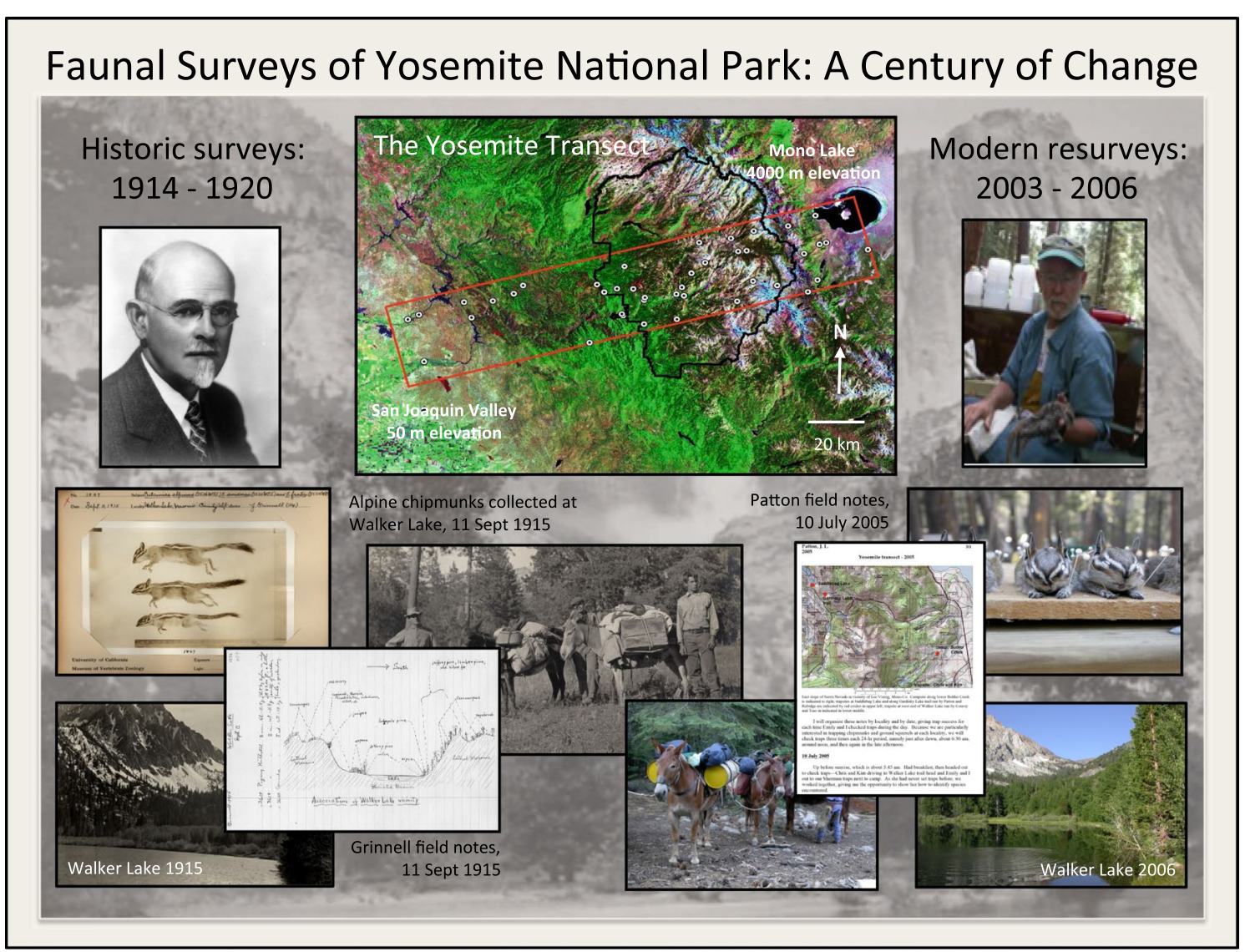

Fig. 2 The Grinnell resurvey project. Surveys of the vertebrates of Yosemite National Park, California, were initiated by Joseph Grinnell in 1914 and continued by James L. Patton and colleagues in 2003. Using Grinnell's detailed specimen locality data, field notes, and photos, researchers were able to replicate closely his sampling efforts nearly a century later. The result is an unprecedented look at biotic responses to nearly a century of environmental change

the collecting sites and largely duplicated the field methods of Grinnell and colleagues. The resurvey effort resulted in the collection of an additional 8500 specimens as well as extensive associated field notes and photos. Together with the results of Grinnell's original surveys of the Yosemite region, these resources provide an unparalleled record of changes in faunal diversity in the central Sierra Nevada over the past $\sim 100$ years.

Starting with the physical specimens collected during the historical and modern Grinnell surveys, research into the impacts of environmental change in Yosemite over the past century has grown to include analyses of temporal changes in multiple aspects of the phenotypes and genotypes of the vertebrates of this region. This includes digital morphometric analyses of changes in cranial structure (Hammond et al. 2016), stable isotope analyses of fur samples to characterize dietary changes (Walsh et al. 2016), and sequencing of genomic DNA to quantify changes in genetic variation (Bi et al. 2012, 2013). In brief, the natural history specimens generated by the Grinnell surveys are at the forefront of research into the ecological and evolutionary consequences of climate change.

\section{The GRP module: integrating research and education}

While the value of the Grinnell surveys to climate change research is immediately apparent, the potential educational value of these materials is just beginning to be realized. The Grinnell data offer important natural history collections-based opportunities to develop creative new approaches to undergraduate STEM education that are consistent with the changes suggested by AAAS's Vision and Change document. In particular, we believe that the Yosemite surveys, as one particularly rich exemplar of the power of natural history collections data, provide an ideal context for engaging students in inquiry-driven learning experiences that promote understanding of relevant biological concepts while simultaneously instilling familiarity with critical analytical skills (Cook et al. 2014). A significant component of the educational value of these 
materials derives from their dynamic nature as resources actively in use as part of research on climate change, rather than canned exercises with pre-determined outcomes. The objectives and content of student activities based on the Grinnell surveys will change as the underlying database grows and changes, thereby allowing students to participate directly in the ongoing exploration of the effects of climate change on the fauna of Yosemite.

\section{Getting started: the MAD response}

When faced with environmental change, populations of organisms tend to move, adapt, or die (the "MAD" response), and evidence for all three of these responses has been observed in a variety of ecological systems (reviewed in Parmesan 2006). The first of these responses-move-is expected to result in changes to a species' geographic distribution, including elevational as well as latitudinal or longitudinal range changes. In contrast, the second response-adapt-may occur in situ, generating quantifiable changes in phenotypes and genotypes as populations respond to new combinations of local selective pressures. The third response-deathresults from the local (and potentially more widespread) extinction of populations of conspecifics. This seemingly simple set of outcomes encompasses a wide range of ecological and evolutionary concepts that are central to understanding patterns and processes of organismal change. As a result, educational activities based on the MAD response to environmental change offer numerous opportunities to integrate fundamental principles and practices in biology education.

\section{Narrowing the scope: chipmunks as focal study organisms} Over the course of the Grinnell surveys, chipmunks (genus Tamias) have emerged as key taxa for studying the impacts of climate change. This emphasis on chipmunks reflects their marked interspecific variation in response to the past century of environmental change, as revealed by comparisons of the historical and modern distributions of these animals in the Sierra Nevada. At the time of Grinnell's original surveys, five species of chipmunks were documented in the Yosemite region, with each species occupying an elevationally distinct band between the western foothills and the crest of the Sierra Nevada (Grinnell and Storer 1924). Four of these species (T. quadrimaculatus, T. senex, T. speciosus, $T$. alpinus) are also represented in the modern Grinnell surveys. Comparisons of trapping localities for conspecifics captured in each time period indicate that two species have undergone significant changes in distribution over the past century (Fig. 3). Specifically, T. senex has largely disappeared from Yosemite during this period while $T$. alpinus has undergone a significant upward contraction of its historical lower elevational range limit (Moritz et al. 2008). Interestingly, T. speciosus, which is partially sympatric with both $T$. senex and T. alpinus, has undergone no significant change in distribution during the same interval.

This difference in response by phylogenetically related, ecologically similar, and at least partially co-occurring species has prompted additional research aimed at identifying the factors that determine their responsiveness to environmental change. Due to the effective absence of $T$. senex in modern surveys, these analyses have focused on comparisons of the lodgepole chipmunk (T. speciosus) and the alpine chipmunk (T. alpinus). Both of these charismatic species are diurnal and herbivorous and hibernate during the long montane winter. Where they co-occur, the two species are readily distinguished by their size ( $T$. speciosus: $50-70 \mathrm{~g}$; T. alpinus: $<50 \mathrm{~g}$ ) and their pattern of pelage stripes. Although few detailed studies have been conducted on the natural history of these animals, $T$. alpinus is generally considered to be more of an ecological specialist than T. speciosus, a difference that may have important implications for patterns of response to environmental change. Ongoing studies are exploring potential relationships among ecology, behavior, physiology, genetic variability, and observed elevational responses by these species over the past century (Bi et al. 2013; Hammond et al. 2015, 2016; Rubidge et al. 2011, 2012; Walsh et al. 2016).

\section{What's the point? goals and objectives}

The educational module described here builds upon collections-based research conducted as part of the GRP to promote both conceptual understanding and acquisition of critical research skills related to climate change. The module consists of three distinct but related sets of inquiry-driven activities that are designed to be used together or as stand-alone exercises. The specific objectives for each part of the module are given at the start of the associated online materials. More generally, using responses to climate change by Yosemite chipmunks as a starting point, each portion of the module introduces students to critical concepts in organismal and evolutionary biology that are relevant to a component of the MAD response. Using these concepts, students develop hypotheses and test predictions regarding the impacts of changing climatic conditions on specific aspects of chipmunk biology. Students then extract, organize, and interpret relevant specimen-based data. By constructing graphs and completing simple statistical tests, students formally test their hypotheses, after which interpretation of these outcomes can be used to relate information contained in museum data back to key concepts and patterns of response to changing climatic conditions. Thus 


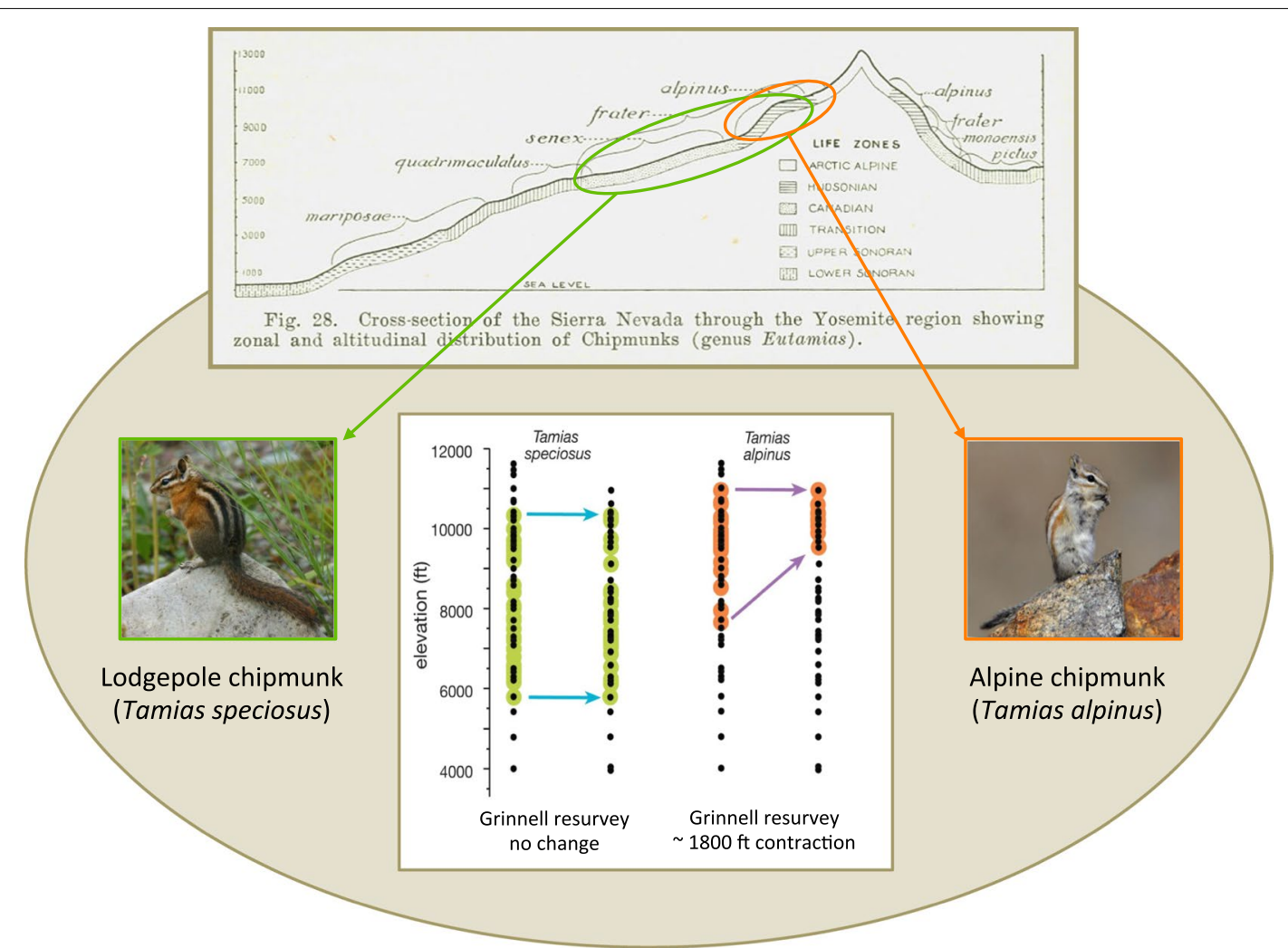

Fig. 3 Elevational range shifts of yosemite chipmunks. Two species of chipmunks have become the focus of efforts to understand interspecific differences in response to climate change in Yosemite National Park. Although the lodgepole chipmunk (Tamias speciosus) and the alpine chipmunk (Tamias alpinus) are closely related and co-occur in portions of the park, they display very different patterns of elevational range response to the past century of environmental change. While the alpine chipmunk has undergone a significant upward shift of its lower elevational range limit, the lodgepole chipmunk has experienced no significant change in its elevational distribution (Moritz et al. 2008; profile map of the Sierra Nevada modified from Grinnell and Storer 1924)

the module uses a real-world example to engage students in the process of scientific inquiry. In particular, the fluid structure of the module promotes active learning and discovery but with sufficient guidance to insure that students master essential biological concepts and achieve competency with fundamental analytical skills.

\section{Module part 1: exploring range changes}

Changes in a species' distributional limits-the $M$ in MAD-provide a common first line of evidence that organisms are responding to environmental change. In the first part of the GRP educational module, students use the elevational records for museum specimens of T. speciosus and T. alpinus from Yosemite to determine if the elevational ranges of these animals have changed over the past century (Fig. 4). While this activity can be completely exploratory (e.g., has either species experienced an elevational range change?), it can also be more hypothesis-driven if students are asked to use basic natural history differences between these species to predict relative patterns of movement in response to environmental change (e.g., is greater habitat specialization associated with a more pronounced change in elevational distribution?). The latter approach requires students to wrestle with fundamental concepts such as ecological specialization, niche width, and elevational changes in habitat conditions. The assumption that $T$. alpinus is more ecologically specialized can be provided as background information or students can arrive at this understanding for themselves by comparing the descriptions of the study species available on Animal Diversity Web (animaldiversity.org). In sum, the degree to which the hypothesis-testing framework for the module is instructor- versus student-generated can be varied to meet the objectives of different courses.

To test predictions regarding interspecific differences in range response, the relevant data can be extracted from the MVZ's publicly accessible database (http://arctos.database.museum/SpecimenSearch.cfm). As is true of any natural history collection database, however, the resulting "raw" information requires review for accuracy prior to use. To simplify this process for instructors, we 

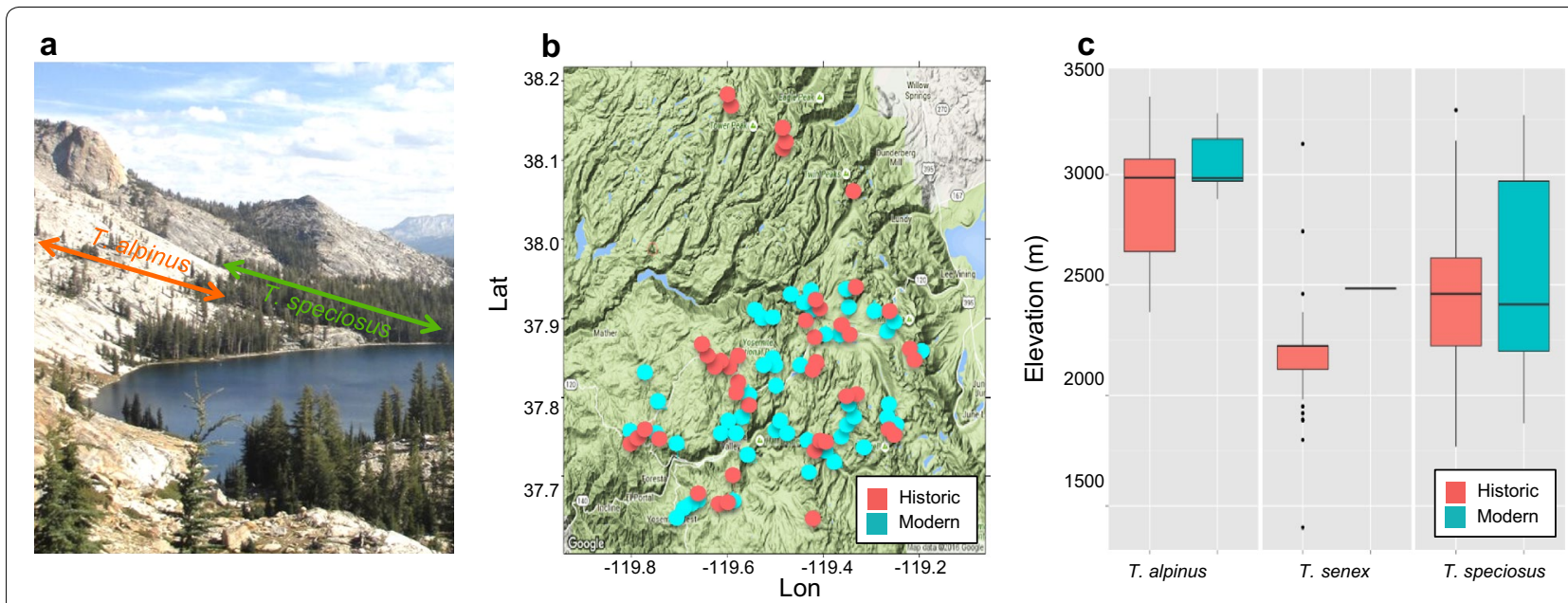

Fig. 4 Module part 1: using online resources, mapping, and statistics in R to understand movement. In the first part of the module, students examine elevational range shifts among Yosemite chipmunks. They use Animal Diversity Web to gather basic information about the focal species, such as which habitats they prefer (a), after which they use an R script provided in the module to map historic and contemporary museum specimen localities (b T. speciosus) and to quantitatively examine the elevational shifts that have occurred over the past century (c). Actual module output generated by students is shown in $(\mathbf{b}, \mathbf{c})$

provide a ready-to-use set of collection localities, including elevations, for the focal study species; these materials are available online as part of the GRP module. As a first step toward analyzing these data, we provide several R-program scripts that map the elevational records for each species (scripts are easily usable even by those who have never worked in R, and an "Introduction to R" activity is also included with the module), first as points on digital maps of Yosemite (Fig. 4b) and then in a more quantitative format that graphically contrasts the range of elevations for historical and modern specimens of each species (Fig. 4c). These procedures allow students to visualize the historical and modern distributions of each species to gain a qualitative understanding of their elevational range shifts. These analyses also open the door for discussion of important considerations such as the impacts of potential sampling biases on conclusions regarding range shifts. To compare the distributions of the two study species quantitatively, as well as to assess intraspecific changes in distribution from historical to modern time periods, simple descriptive parameters (e.g., means and standard deviations) and two-sample statistical tests (e.g., t-tests) can be used. Background reading, detailed instructions, and suggestions for completing each of these analytical steps are provided online in the module.

\section{Module part 2: examining evidence of adaptation}

Local adaptation-the A in MAD-represents a second potential response to environmental change. Local adaptation may occur as an alternative to or in conjunction with changes in species' distributions, adding an important dimension of complexity to studies of the effects of climate change. The second part of the GRP module explores potential evidence of in situ change in cranial morphology and genetic variation. Again, exploration of data regarding in situ change can be hypothesisdriven, as the published literature provides evidence for two potential alternative outcomes. Specifically, relative to species that fail to move, species that undergo range changes may experience (1) greater in situ adaptation in the novel environments encountered as a result of distributional changes or (2) reduced in situ adaptation because changes in distribution allow them to track-i.e., to continue to inhabit-preferred habitats. These hypotheses incorporate critical evolutionary concepts such as adaptation, natural selection, phenotypic change, and the role of environmental conditions in establishing local selective pressures.

To test the two hypotheses outlined above, the GRP module employs the extensive ancillary data sets developed from specimens of T. alpinus and T. speciosus collected in Yosemite (Fig. 1). To explore potential adaptive changes in cranial structure (a possible signal of changes in environmental conditions), students analyze morphological measurements made from the skulls of these animals, in the process considering how cranial structure may be related to differences in diet, respiratory physiology, and olfactory exploration of the environment (Fig. 5a, b). Files containing the necessary stable isotope 


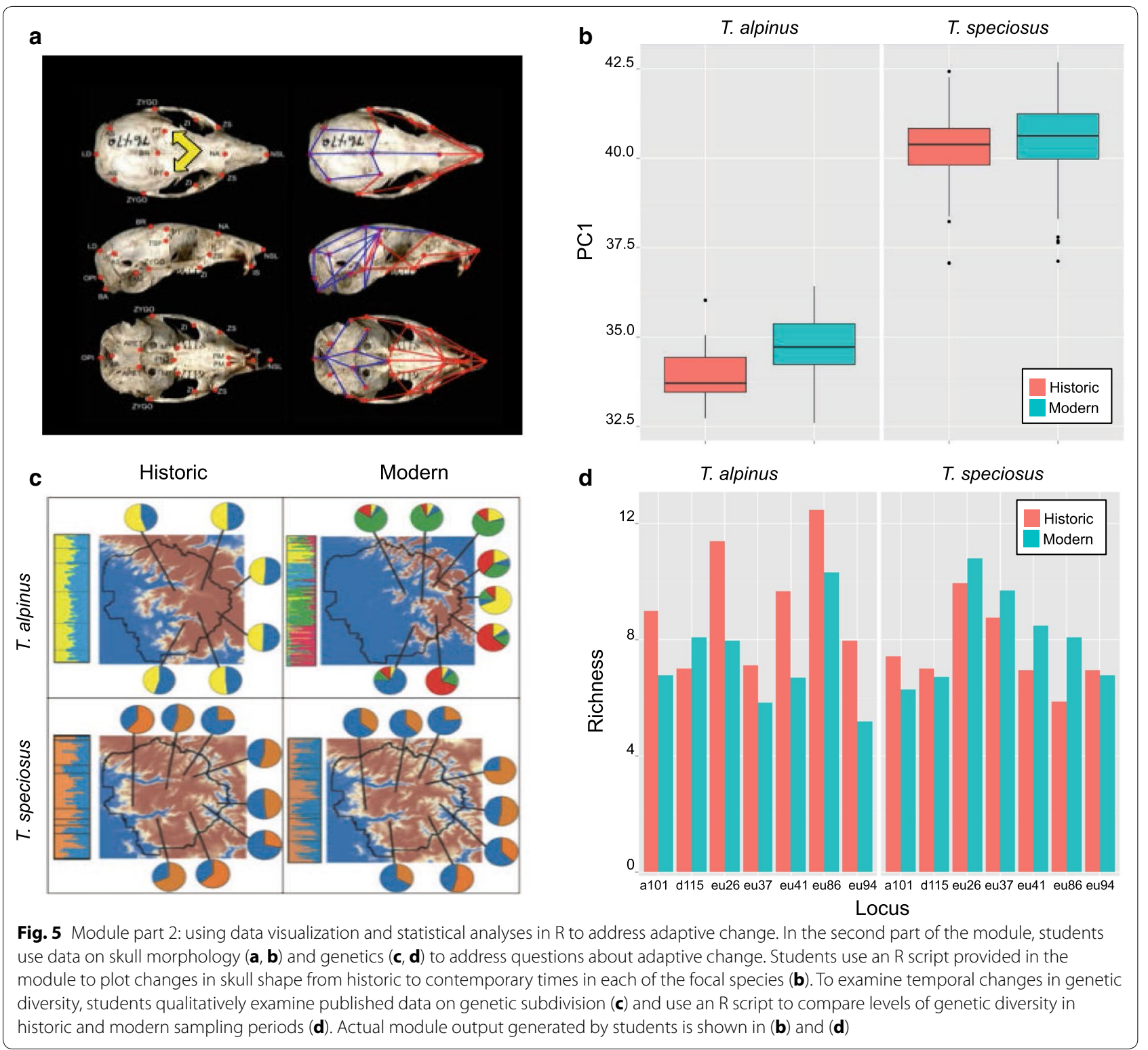

and morphological information are provided with the GRP module, along with guidelines and suggestions for analyzing these data sets.

The types of changes outlined above may result from phenotypic plasticity (the ability of a single genotype to express different phenotypes in different environments) or may reflect evolutionary change (selection for different phenotypes over multiple generations). Over time, the latter is expected to be associated with genotypic changes in the study organisms. More generally, range changes as well as demographic responses to climate change may affect genetic variability within populations, and thus exploration of patterns of genetic structure represents a critical component of characterizing potential responses to changing environmental conditions. Accordingly, students can also use this part of the GRP module to examine changes in genetic structure over the course of the Grinnell surveys (Fig. 5c, d). Relationships between habitat use, demography, and genetic variation are complex. However, by focusing on the effects of the upward range contraction by T. alpinus on the continuity of the habitats occupied by this species, students should be able to generate testable predictions regarding relative changes in genetic variability in the two study species over the past century. To explore these ideas, the module includes a file containing genotypic data (analyses of 7 microsatellite 
loci; Rubidge et al. 2012) for the focal species (Fig. 5d). Suggestions and guidelines for conducting simple comparative, quantitative analyses of genetic variability in the study species are also provided.

\section{Module part 3: what about "missing" populations?}

Death-the D in MAD-is a third potential response to climate change. Depending upon the scale at which mortality occurs, it may result in extirpation of local populations or more extensive extinctions that, in extreme cases, result in the complete loss of a species. A growing body of evidence suggests that even local extinctions in response to climate change may have profound impacts on communities of organisms and thus the loss of individuals, populations, and species is of considerable interest to evolutionary as well as conservation biologists (Blois et al. 2013; Lurgi et al. 2012). With regard to the GRP, the almost complete absence of $T$. senex from modern surveys is thought to reflect the extirpation of these animals. Although populations of this species persist elsewhere in California, they are now thought to be largely absent from Yosemite. At a much more local scale, the upward range contraction of $T$. alpinus may also reflect extirpation, in this case the loss of local populations that had been resident at the elevations that were historically occupied by this species. Although some individuals may have moved to higher elevations, the pattern of range contraction by this species coupled with the pattern of generally exclusive use of home ranges by these animals (Chappell 1978; Heller 1971) makes it unlikely that entire populations of alpine chipmunks have moved uphill as environmental conditions have changed. Thus, loss of populations due to local extirpation appears to be an integral part of the GRP findings.

In addition to being fundamental concepts in evolutionary biology, extirpation and extinction pose important analytical challenges for the types of field surveys that form the core of the GRP effort. While evidence that a species was present at a given point in space and time is largely irrefutable (the specimen is the proof!), unambiguous evidence that a species is absent is more difficult to obtain. As a result, statistical analyses of occurrence data must take into account parameters such as the probability of detecting an organism, a value that can differ markedly among species (MacKenzie et al. 2005). While an in-depth quantitative analysis of this problem is beyond the scope of the GRP module, we believe that the conceptual challenge of working with presence-absence data is an important topic for students to consider; in addition to being the basis for the $\mathrm{D}$ portion (and a potential part of the $\mathrm{M}$ portion) of the MAD response, absence data may have significant practical implications (is a "missing" species really extinct?). As a result, analyses of absence data provide the basis for important discussions regarding the foundations of the scientific method. In Part 3 of the GRP module, students use historic and modern data on the presence of chipmunks to develop simple ecological niche models that predict where each species should persist in the future (Fig. 6). As part of this activity, students can use a modified data set provided in the module to explore the effect of changes in detectability of the study species on these future projected ranges.

\section{Customizing the module for your classroom}

As the previous sections indicate, the GRP module includes a series of activities aimed at engaging students in direct exploration of specimen-based data relevant to studies of climate change. An important feature of the module is that these materials can be tailored to meet the diverse needs of different courses. For students that require more structure, the online resources can be used verbatim to guide classroom activities. For students capable of working more independently, the online materials may be more effective as demonstrations of the types of analyses that can be conducted using natural history collections data. Depending upon the educational goals, instructional level, and time available to students, the activities outlined in the module can be completed during a single several-hour period or they can be expanded to form the basis for semester-long student projects. With regard to the latter, once students have become familiar with the nature of the GRP data set, they can expand their inquiries to consider other taxa or to consider other regions of the planet for which historical and modern records exist. This flexibility is a critical feature of the GRP module that should enhance its utility to instructors. Indeed, we hope that one consequence of making these materials widely available is the emergence of new opportunities to collaborate with undergraduate educators to improve the utility of the module and to assess quantitatively the effectiveness of this tool for enhancing STEM education.

\section{Did it work? Assessing student performance}

An essential component of most educational activities is the assessment of the impacts of those experiences on student knowledge and understanding. Because the goals of student assessment differ among instructors, courses, and institutions (Andersen and Rogan 2010), it is challenging to provide a single, broadly applicable assessment plan for the GRP module. In our initial testing of these materials we employed an informal formative assessment strategy based on student input regarding the clarity of the background information and instructions provided; this focus reflects the process of creating the module. Now, as we segue to evaluating the educational impact 


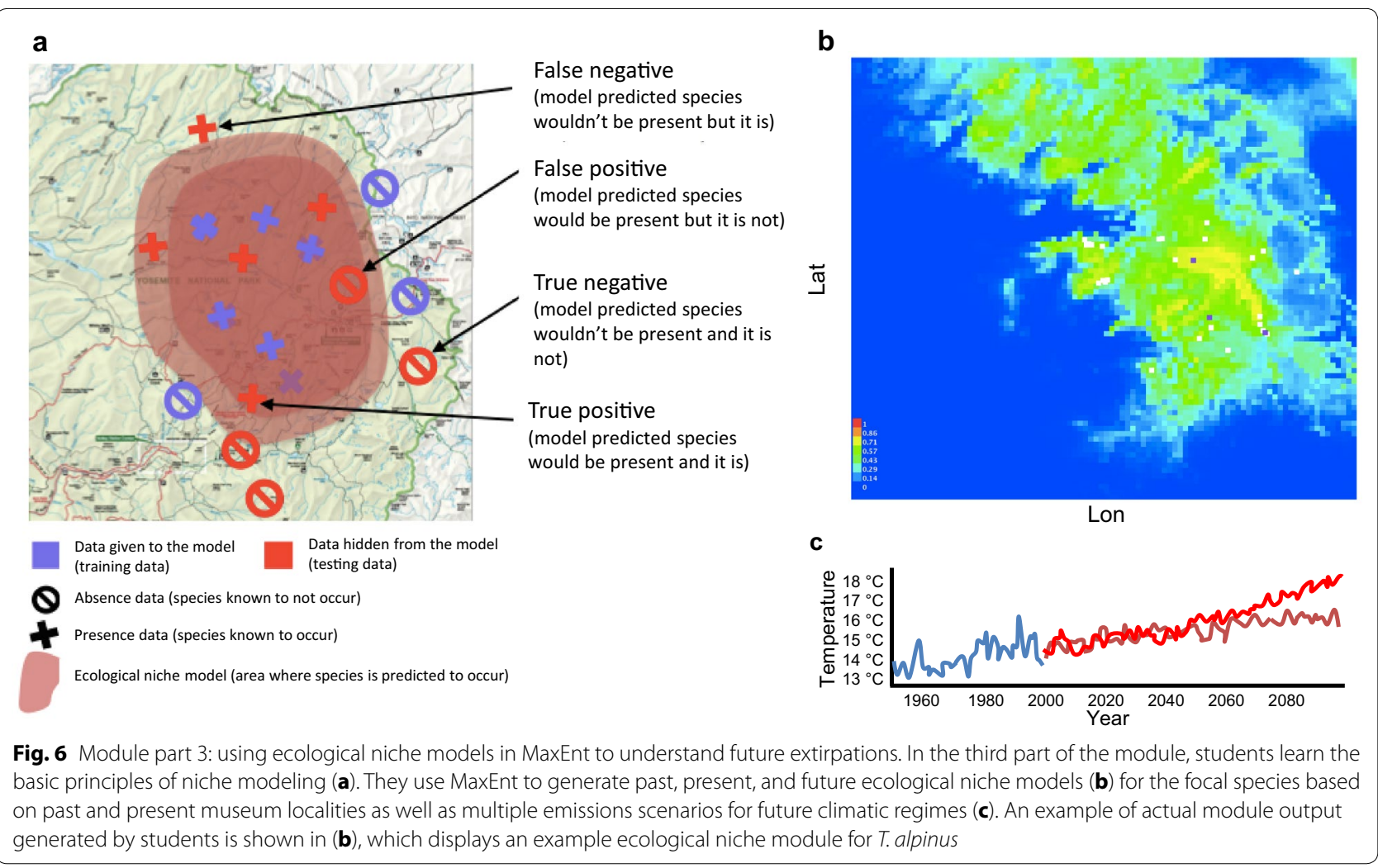

of the module, we are developing different assessment tools such as pre- and post-activity quizzes that measure gains in understanding of associated biological concepts and pre- and post-activity surveys that assess changes in student understanding of the nature and scientific value of natural history collections. We note that the module lends itself to multiple forms of quantitative assessment, including evaluation of student gains in core competencies and concepts identified as critical to undergraduate science education (Brewer and Smith 2011). The module also provides a foundation for quantitative and qualitative assessment of changes in student attitudes toward the scientific process, climate change, and natural history collections (Zeidler et al. 2002; Reid 2006; Semsar et al. 2011). In sum, just as the module has been designed to be adaptable to a range of specific instructional goals, its success as an educational activity can be evaluated using an array of procedures.

\section{Bringing it home: place-based studies of climate change}

Anthropogenic climate change is a global phenomenon, the effects of which can vary markedly over sometimes limited spatial scales (Parmesan 2006). One important means of increasing student engagement in educational activities is to make those experiences place-based-that is, to make them local and therefore relevant to a specific group of students (Orr 1994). Place-based learning has been shown to increase pro-environmental behavior (Scannell and Gifford 2010), to provide a strong predictor of efforts to improve environmental quality (Johnson et al. 2012), and to represent a potentially important tool for promoting acceptance of climate change as a phenomenon of critical concern (Borick and Rabe 2010; Brownlee et al. 2013). Indeed, place-based education provides a general framework for improving ecological-and therefore biological-literacy (Jordan et al. 2009).

The types of inquiry-driven activities outlined in the GRP module offer important opportunities for instructors to engage students in place-based studies of climate change. Natural history specimens provide evocative connections between science and our daily lives; such specimens represent real organisms that at one time also called a given locale "home" and that students may have observed in nature. The field notebooks and images associated with those specimens are artifacts left by named individuals who visited places known to the students in question. This connection to the familiar is critical, as it serves to make the complicated processes and complex outcomes of climate change relevant in ways that examples drawn from distant and unfamiliar locations cannot. Thus, it allows instructors to use salient local features as a foundation for enhancing conceptual understanding of biology (Sobel 2004). 
The importance of place-based examples to ecological literacy, environmental advocacy, and climate change education has been articulated in multiple recent publications (Borick and Rabe 2010; Brownlee et al. 2013; Johnson et al. 2012; Jordan et al. 2009; Scannell and Gifford 2010). Schweizer et al. (2013) proposed that America's national parks and wildlife refuges should serve as focal points for this kind of environmental education. While the GRP module focuses on an iconic national park, we believe that place-based connections with the environment can and should be extended to encompass any number of local settings, including natural areas on urban university campuses. Multiple factors contribute to creating a sense of place (Kudryavtsev et al. 2012) and, accordingly, establishing connections may be more challenging for some settings than for others. In the context of this article, not all localities will have natural history specimens associated with them, thereby limiting opportunities to create activities similar to the GRP module. However, the range of locations worldwide for which museum specimens are available and the ready online access to natural history collections data increase the probability that local exemplars can be identified for numerous groups of students. Thus, while the Yosemite study system offers a particularly rich data set around which to build an educational module, we encourage educators to be creative and to explore the vast array of information contained in natural history collections to provide critical STEM training in the context of exploring local effects of climate change.

\section{Creating a network of MAD observatories}

The GRP module emphasizes the use of natural history collections data in undergraduate education. Such data represent invaluable resources for engaging students in learning activities that are consistent with STEM principles, and, importantly, these natural history "big data" are now available to educators at institutions without collections, thereby greatly increasing the potential impact of natural history specimens and specimen data on undergraduate education. A related outcome of the emergence of "big data" has been an increased emphasis on alternative forms of natural history information, including increased use of observations collected as part of citizen science efforts (Silvertown 2009). While physical specimens provide a critical permanent record of biodiversity, the importance of reliable locality information collected by students and non-scientists is growing. Acceptance of these types of information increases the potential for students to engage directly in the generation of biodiversity data, thereby providing an additional means of making learning experiences place-based.
The ability of students to collect their own biodiversity data creates exciting, synergistic new opportunities for undergraduate education. Among these is the potential to establish a national or international network of student-driven MAD "observatories." Each observatory would be the result of campus-specific learning activities that integrate use of existing digital natural history resources with collection of new, local biodiversity data. Aggregating these efforts across multiple institutions would create a novel and important resource that would not only enhance undergraduate training in STEM disciplines, but would also further climate change research. Thus, the merger of natural history collections with "big data" bioinformatics may help to solve big problems such as the impacts of climate change on global biodiversity.

\section{Implications for science education}

Although the GRP module emphasizes climate change, we believe that the pedagogical approach and instructional strategies encompassed by the module have implications for biology education that extend well beyond the scope of this or any specific topic. Recent calls for reform in biology education emphasize the need for (1) improved integration of concepts and facts with the process of scientific inquiry, (2) active, rather than passive learning experiences, and (3) authentic exposure to biology, including exposure to the variability and unpredictability inherent to natural systems (Brewer and Smith, 2011). The activities outlined in the GRP module are consistent with each of these goals: the module describes inquiry-driven learning experiences that require students to integrate multiple types of data and analytical skills to test hypotheses based on current, real-world problems. In particular, the module uses emerging "big data" resources to examine information obtained from fieldbased specimens, thereby generating a critical intersection between bioinformatics, computational biology, and natural history. These learning experiences are active and authentic in that students engage in the process of analyzing the effects of climate change using information drawn from a "living" database that is constantly changing as new specimens and associated records are added. While the module is structured around concepts, questions, and analyses related to climate change, it can also readily serve as a template for similar instructional efforts on the vast array of biological topics that are informed by natural history specimens (Cook et al. 2014).

\section{Conclusions}

Biology education is at a crossroads. Traditional, largely passive approaches to undergraduate education (e.g., large, lecture format courses; memorization-driven evaluative methods) are not effective at preparing students to 
participate directly in efforts to resolve emerging global challenges such as climate change. As a result, new educational strategies are required to train future generations of scientists as well as to increase public science literacy. As we have argued here, natural history collections and the increasingly rich and diverse data sets associated with these specimens represent critical but largely untapped resources for revolutionizing undergraduate education in biology, particularly in the fields of evolution and ecology. Now, in the era of "big data," natural history collections offer significant opportunities to engage students in inquiry-driven, place-based exercises that integrate fundamental biological concepts with efforts to understand emerging conservation and societal issues such as climate change. As illustrated by the GRP module, these exercises can be tailored to meet a wide range of educational objectives and levels of instruction. As use of these resources grows, we expect that exciting new ideas and opportunities will emerge, thereby further solidifying the role of natural history collections in undergraduate education. The associated changes to the process of biology education will benefit all of us through improved training of future generations of scientists and citizens-the individuals who will be at the forefront of resolving the complex challenges that lie ahead.

\section{Abbreviations \\ GRP: Grinnell Resurvey Project; MAD: move, adapt, or die; MVZ: Museum of Vertebrate Zoology.}

\section{Authors' contributions}

The educational module described in the manuscript grew out of seminar on the role of natural history collections in studies of climate change conducted jointly at the University of New Mexico (JAC), the University of California, Berkeley (EAL), Harvard University (SVE), and the University of Alaska Fairbanks (SIB); this seminar was sponsored by the AIM-UP! network, a Research Coordination Network in Undergraduate Biology Education sponsored by the National Science Foundation (NSF DEB-0956129). EAL took primary responsibility for writing the manuscript; TTH and REW were primarily responsible for the content of the associated module. All other authors participated in one or more workshops sponsored by the AIM-UP! network and read and provided constructive feedback on drafts of the manuscript. All authors read and approved the final manuscript.

\footnotetext{
Author details

${ }^{1}$ Museum of Vertebrate Zoology \& Department of Integrative Biology, University of California, Berkeley, CA 94720-3140, USA. ${ }^{2}$ Museum of Southwestern Biology \& Biology Department, University of New Mexico, Albuquerque, NM 87131, USA. ${ }^{3}$ Museum of Comparative Zoology \& Department of Organismic and Evolutionary Biology, Harvard University, Cambridge, MA 02138, USA. ${ }^{4}$ Department of Biological Science, Florida State University, Tallahassee, FL 32306, USA. ${ }^{5}$ Florida Museum of Natural History, University of Florida, Gainesville 32611, FL, USA. ${ }^{6}$ Museum of the North \& Department of Biology and Wildlife, University of Alaska, Fairbanks, AK 99775, USA. ${ }^{7}$ Moore Laboratory of Zoology \& Biology Department, Occidental College, Los Angeles, CA 90041, USA. ${ }^{8}$ Central Michigan University Herbarium \& Department of Biology, Central Michigan University, Mount Pleasant, MI 48859, USA. ${ }^{9}$ Department of Biology, University of Florida, Gainesville 32611, FL, USA.
}

\section{Acknowledgements}

The authors would like to thank the numerous colleagues who have participated in AIM-UP!, a Research Coordination Network in Undergraduate Biology Education sponsored by NSF DEB-0956129. The idea for an educational module focused on the use of natural history collections to understand climate change grew out of an AIM-UP! sponsored seminar conducted jointly at UC Berkeley, the University of New Mexico, Harvard University, and the University of Alaska Fairbanks during the spring of 2014. We thank the students at each of these institutions who participated in the seminar. In addition, we thank the many participants in the Museum of Vertebrate Zoology's Grinnell Resurvey Project, in particular Craig Moritz and James L. Patton for their insights and suggestions.

\section{Competing interests}

The authors confirm that they have no competing interests to acknowledge regarding the educational module described in this publication.

\section{Availability of data and materials}

The datasets and materials that comprise the educational module described in the text are available in the AIM-UP "For Educators" repository, and can be found at the following link: http://aimup.unm.edu/for-educators/Climate\%20 change.html.

\section{Funding}

This work was supported by an NSF funded Research Coordination Network in Undergraduate Biology Education, NSF DEB-0956129.

\section{Publisher's Note}

Springer Nature remains neutral with regard to jurisdictional claims in published maps and institutional affiliations.

Received: 20 September 2016 Accepted: 8 May 2017

Published online: 22 May 2017

\section{References}

Altizer S, Ostfeld RS, Johnson PTJ, Kutz S, Harvell CD. Climate change and infectious diseases: from evidence to a predictive framework. Science. 2013;341:514-9.

Andersen TR, Rogan JM. Bridging the educational research-teaching practice gap. Biochem Mol Biol Educ. 2010;38:51-7.

Bi K, Vanderpool D, Singhal S, Linderoth T, Moritz C, Good JM. Transcriptome-based exon capture enables highly cost-effective comparative genomic data collection at moderate evolutionary scales. BMC Genom. 2012;13:403.

Bi K, Linderoth T, Vanderpool D, Good JM, Nielsen R, Moritz C. Unlocking the vault: next-generation museum population genomics. Mol Ecol. 2013;22:6018-32.

Blois JL, Zarnetske PL, Fitzpatrick MC, Finnegan S. Climate change and the past, present, and future of biotic interactions. Science. 2013;341:499-504.

Borick CP, Rabe BG. A reason to believe: examining the factors that determine individual views on global warming. Soc Sci Quart. 2010;91:777-800.

Brewer CA, Smith D, editors. Vision and change in undergraduate biology education: a call to action. Washington D.C.: American Association for the Advancement of Science; 2011

Brownlee MTJ, Powell RB, Hallo JC. A review of the foundational processes that influence beliefs in climate change: opportunities for environmental education research. Environ Educ Res. 2013;19:1-20.

Chappell MA. Behavioral factors in the altitudinal zonation of chipmunks (Eutamias). Ecology. 1978;59:565-79.

Cook JA, Edwards SV, Lacey EA, Guralnick RP, Soltis PS, Soltis DE, Welch C, Bell KC, Galbreath KE, Himes C, Allen JM, Heath TA, Carnaval AC, Cooper KL, Liu M, Hanken J, Ickert-Bond S. Natural history collections as emerging resources for innovative education in biology. Bioscience. 2014:64:725-34. 
Cook J, Lacey E, Ickert-Bond S, Hoberg E, Galbreath KE, Bell KC, Greiman SE, McLean BS, Edwards SV. From museum cases to the classroom: emerging opportunities for specimen-based education. In: Pavlinov Y (Ed.) Aspects of Biodiversity II Archives of the Zoological Museum of Moscow State University, 54, 787-799.

Graham CH, Ferrier S, Huettman Moritz, Peterson AT. New developments in museum-based informatics and applications in biodiversity analysis. Trends Ecol Evol. 2004;19:497-503.

Grinnell J. The methods and uses of a research museum. Pop Sci Mon. 1910;77:163-9.

Grinnell J, Storer TI. Animal life in Yosemite. Berkeley: University of California Press; 1924

Hammond TT, Springthorpe D, Walsh RE, Berg-Kirkpatrick T. Using accelerometers to remotely and automatically characterize behavior in small animals. J Exp Biol. 2016;219(11):1618-24.

Hammond TT, Palme R, Lacey EA. Contrasting stress responses of two cooccurring chipmunk species (Tamias alpinus and T. speciosus). Gen Comp Endocrinol. 2015:211:114-22.

Hanewinkel M, Cullmann DA, Schelhaas M-J, Naburrs G-J, Zimmermann NE. Climate change may cause severe loss in the economic value of European forest land. Nat Clim Change. 2013;3:203-7.

Hannah L, Roehrdanz PR, Ikegami M, Shepard AV, Shaw MR, Tabor G, Zhi L, Marquet PA, Hijmans RJ. Climate change, wine, and conservation. Proc Natl Acad Sci. 2013;110:6907-12

Heller HC. Altitudinal zonation of chipmunks (Eutamias): interspecific aggression. Ecology. 1971;52:312-9.

Holmes MW, Hammond TT, Wogan GO, Walsh RE, LaBarbera K, Wommack EA, Martins FM, Crawford JC, Mack KL, Block LM, Nachman MW. Natural history collections as windows on evolutionary processes. Mol Ecol. 2016;25:864-81.

IPCC (2014) Climate change 2014: synthesis report. Contribution of working groups I, II, and III to the fifth assessment report of the intergovernmental panel on climate change. In: Pachauri RJ, Meyer LA (Eds.) Geneva: IPCC; 2014

Johnson B, Duffin M, Murphy M. Quantifying a relationship between place-based learning and environmental quality. Environ Educ Res. 2012;18:609-24.

Jordan R, Singer F, Vaughan J, Berkowitz A. What should every citizen know about ecology? Front Ecol Environ. 2009;7:495-500.

Kudryavtsev A, Stedman RC, Krasny ME. Sense of place in environmental education. Environ Educ Res. 2012;18:229-50.

Kutz SJ, Jenkins EJ, Veitch AM, Ducrocq J, Polley L, Elkin B, et al. The Arctic as a model for anticipating, preventing, and mitigating climate change impacts on host-parasite interactions. Vet Parasitol. 2009;163:217-28.

Lister AM, The Climate Change Research Group. Natural history collections as sources of long-term datasets. Trends Ecol Evol. 2011;26:153-4.

Lurgi M, Lopez BC, Montoya JM. Novel communities from climate change. Philos Trans R Soc Ser B. 2012;367:2913-22

MacKenzie DI, Nichols JD, Sutton N, Kawanishi K, Bailey LL. Improving inferences in population studies of rare species that are detected imperfectly. Ecology. 2005;86:1101-13.

Melillo JM, Richmond TT, Yohe G. Climate change impacts in the United States: the third national climate assessment. US Global Change Research Program. nca2014. globalchange. gov. 2014.

Monfils AK, Powers KE, Marshall CJ, Martine CT, Smith JF, Prather AL. Natural history collections: teaching about biodiversity across time, space, and digital platforms. Southeastern Naturalist (in press).

Moritz C, Patton JL, Conroy CJ, Parra JL, White GC, Beissinger SR. Impact of a century of climate change on small-mammal communities in Yosemite National Park, USA. Science. 2008;322:261-4.

Nelson GC, Valin H, Sands RD, Havlik P, Ahammad H, Deryng D, Ellott J, Fujimori S, Hasegawa T, Heyhoe E, Kle P, Von Lampe M, Lotze-Campen H, d'Croz DM, van Meiji H, van der Mensbrugghe D, Muller C, Popp A, Robertson R, Robinson S, Schmid E, Schmitz C, Tabeau A, Willenbockel D. Climate change effects on agriculture: economic responses to biophysical shocks. Proc Natl Acad Sci. 2014;111:3274-9.
NIBA. A strategic plan for establishing a network integrated biocollections alliance. http://digbiocol.wordpress.com/brochure. 2010.

Orr DW. Earth in mind: on education, environment, and the human prospect. Washington, D.C.: Island Press; 1994.

Page LM, MacFadden BJ, Fortes JA, Soltis PS, Riccardi G. Digitzation of biodiversity collections reveals biggest data on biodiversity. BioSci Adv Access. 2015. doi:10.1093/biosci/biv104

Parmesan C. Ecological and evolutionary responses to recent climate change. Ann Rev Ecol Evol Syst. 2006;37:637-69.

PCAST (President's Council of Advisors on Science and Technology). Engage to excel: producing one million additional college graduates with degrees in science, technology, engineering and mathematics. https://www. whitehouse.gov/administration/eop/ostp/pcast/docsreports. 2012.

Plutzer E, McCaffrey M, Hannah AL, Rosenau J, Berbeco M, Reid AH. Climate confusion among U.S. teachers. Science. 2016;351:664-5.

Ponder WF, Carter GA, Flemons P, Chapman RR. Evaluation of museum collection data for use in biodiversity assessment. Conserv Biol. 2001;15:648-57.

Powers KE, Prather LA, Cook JA, Woolley J, Bart HI Jr, Monfils AK, Sierwald P. Revolutionizing the use of natural history collections in education. Sci Educ Rev. 2014;13:24-33.

Pyke GH, Ehrlich PR. Biological collections and ecological/environmental research: a review, some observations and a look to the future. Biol Rev. 2010;85:247-66.

Reid N. Thoughts on attitude measurement. Res Sci Technol Educ. 2006;24:3-27

Rowe KC, Rowe KMC, Tingley MW, Koo MS, Patton JL, Conroy CJ, Perrine JD, Beissinger SR, Moritz C. Spatially heterogeneous impact of climate change on small mammals of montane California. Proc R Soc Ser B. 2014;282:1-10.

Rubidge EM, Monahan WB, Parra JL, Cameron SE, Brashares JS. The role of climate, habitat, and species co-occurrence as drivers of change in small mammal distributions of the past century. Global Change Biol. 2011:17:696-708

Rubidge EM, Patton JL, Lim M, Burton AC, Brashares JS, Moritz C. Climateinduced range contraction drives genetic erosion in an alpine mammal. Nat Clim Change. 2012;2:285-8.

Scannell L, Gifford R. The relations between natural and civic place attachment and pro-environmental behavior. J Environ Psychol. 2010;30:289-97.

Schweizer S, Davis S, Thompson JL. Changing the conversation about climate change: a theoretical framework for place-based climate change engagement. Environ Commun. 2013;7:42-62.

Semsar K, Knight JK, Birol G, Smith MK. The Colorado learning attitudes about science survey (CLASS) for use in biology. CBE Life Sci Educ. 2011;10:268-78.

Silvertown J. A new dawn for citizen science. Trends Ecol Evol. 2009;24:467-71.

Sobel D. Place-based education: connecting classrooms and communities. Great Barrington: The Orion Society; 2004.

Tingley MW, Monahan WB, Beissinger SR, Moritz C. Birds track their Grinnellian niche through a century of climate change. Proc Natl Acad Sci. 2009;106:19637-43.

Vermeulen SJ, Campbell BM, Ingram JSI. Climate change and food systems. Ann Rev Environ Res. 2012;37:195-222.

Walsh RE, Assis APA, Patton JL, Marroig G, Dawson TE, Lacey EA. Morphological and dietary responses of chipmunks to a century of climate change. Global Change Biol. 2016:22:3233-52.

Wandeler P, Hoeck PEA, Keller LF. Back to the future: museum specimens in population genetics. Trends Ecol Evol. 2007;22:634-42.

Wen J, Ickert-Bond SM, Appelhans MS, Dorr LJ, Funk VA. Collections-based systematics: opportunities and outlook. J Syst Evol. 2015;53:477-88.

Zeidler DL, Walker KA, Ackett WA, Simmons ML. Tangled up in views: beliefs in the nature of science and responses to socioscientific dilemmas. Sci Educ. 2002;86:343-67. 